\title{
SIMPOSIO INTERNACIONAL SOBRE «LA CIUDAD ISLÁMICA»
}

\author{
Por \\ FRANCISCO FRANCO SÁNCHEZ
}

En la Facutad de Filosofía y Letras de la Universidad de Zaragoza y organizado por el Dr. José Luis Corral, de la Sección de Historia y de Ciencias Historiográficas de la Institución Fernando el Católico de la Excma. Diputación Provincial de Zaragoza, y el Dr. Míkel de Epalza, de la Sección de Estudios Árabes e Islámicos de la Facultad de Filosofía y Letras de la Universidad de Alicante, tuvo lugar el Simposio Internacional sobre «La Ciudad Islámica» entre los días 1 y 4 del pasado mes de diciembre.

El día uno de diciembre, jueves, a las 9.30 horas fue inaugurado el Simposio; en el acto hablaron el Dr. José Luis Corral y el Dr. Míkel de Epalza, como representantes de los organismos patrocinadores del Simposio, agradeciendo el número elevado de estudios presentados al mismo y los apoyos obtenidos de las diversas instituciones. Seguidamente, el primer turno de ponencias fue abierto por el Dr. Jean Bisson (del Instituto de Geografía de la Universidad de Tours), que habló de los «Estudios actuales sobre el urbanismo musulmán en el URBAMA». Después del Dr. Bisson, el Dr. José Luis Corral expuso su ponencia «Del urbanismo musulmán al urbanismo cristiano: las ciudades de la Marca Superior de Al-Andalus». Tras este turno de ponencias de la mañana, y después de un breve descanso se expusieron las comunicaciones de doña Pilar Galve Izquierdo sobre un "Conjunto arqueológico de época emiral en Zaragoza", don Bernabé Cabañero Subiza sobre "La medina islámica de Olite: claves para el estudio de su conjunto amurallado" y la comunicación de don Francisco Javier García Marco sobre el «Espacio urbano en las aljamas mudéjares del Jalón y del Jiloca medios»; después de estas comunicaciones tuvo lugar un animado debate. 
Por la tarde, se expusieron las ponencias del Dr. José Corral (de la Escuela Técnica Superior de Arquitectura de Madrid) sobre el "Espacio, forma y materia en la arquitectura áulica del Islam: La Alhambra de Granada»; don Julián Esteban (Director General de Conservación del Patrimonio de la Generalitat Valenciana) sobre la «Política legal para la conservación de monumentos islámicos en Españan y el Dr. Patrice Cressier (de la Casa de Velázquez de Madrid) sobre el urbanismo de "La ciudad islámica sahariana». Tras ella, doña Clara Delgado Valero expuso su comunicación acerca de la "Estructura urbana de Toledo en la época islámica».

El viernes siguiente, día dos de diciembre, por la mañana empezó el turmo de intervenciones con la ponencia del Dr. Abdel-Hakim El Gafsi (del Centro de Estudios Hispano-Andalusíes de Túnez) acerca del «Urbanismo de poblaciones rurales andalusíes del siglo XV $\|_{\eta}$, sobre el propiciado por los moriscos expulsados de España en Túnez. Seguidamente el Dr. Gilles Veistein (del Instituto de Estudios sobre el Mundo Otomano y el Dominio Turco de la Universidad de La Sorbona de París) expuso su ponencia sobre los problemas que plantea "La ciudad otomana». El turno de mañana se cerró con la exposición de la comunicación de Francisco Franco Sánchez sobre el «Estudio comparativo del urbanismo islámico de seis localidades de la Vía Augusta: Sagunto / Xàtiva / Orihuela y Ontinyent / Bocairent / Benexama». Tras un corto e interesante debate, todos los participantes en el Simposio acudimos en los autobuses puestos al efecto para realizar una visita al Palacio de la Aljafería de Zaragoza.

La visita a la Aljafería fue ilustrada por las explicaciones histórica del Dr. José Luis Corral y artístico-arqueológica de don Bernabé Cabañero Subiza. Una vez recorrido el recinto de la restaurada Aljafería, entramos al Palacio de las Cortes de Aragón, ubicado en el interior del edificio islámico; allí nos fue explicado el significado de la hištórica institución aragonesa y el sentido de la ubicación de la misma en este lugar. Seguidamente tomó la palabra el Dr. Jean Louis Miège, de la Universidad de Aix-en-Provence, historiador de Mágreb árabe y Director del «Programa sobre el Agua y Poblamiento en el Mediterráneo", como patrocinador del Simposio, para agradecer la acogida de la Institución aragonesa, su trabajo a los organizadores del Simposio y su asistencia a los participantes en el mismo, resaltando la importancia y trascendencia en el panorama científico actual de los estudios sobre el urbanismo musulmán.

Ya en la sesión de tarde se siguió con el turno de ponencias. En primer lugar habló el Dr. Enrique Llobregat Conesa (Director del Museo Arqueológico Provincial de Alicante) sobre el paso «De la ciudad visigótica a la ciudad árabe», aportando una serie de interesantes ejemplos de este paso documentado en el Sharq Al-Andalus. Tras él, el Dr. Juan Abellán (de la Universidad de Cádiz) expuso su ponencia "Del urbanismo musulmán al urbanismo cristiano (1); Andalucía Occidental», mientras que el Dr. Manuel Espinar (de la Universidad de Granada) hizo lo propio "Del urbanismo musulmán al urbanismo cristiano (II); Andalucía Occidental». Seguidamente, tras un breve descanso, ya dentro del turno de comunicaciones, disertó don Agustín Sanmiguel Ma- 
teo sobre un "Apunte sobre la evolución urbana del Calatayud musulmán»; después, el Dr. Alfonso Carmona González intervino hablando sobre el paso "De lo romano a lo árabe; el surgimiento de la ciudad de Murcia» y don Sebastián Fernández López, expuso el interesante urbanismo de un yacimiento islámico en su comunicación sobre "Marmuyas (Montes de Málaga); Urbanismo musulmán en su ámbito rural».

En la sesión científica del sábado tres, el turno de las ponencias por la mañana fue abierto por el Dr. Pedro Chalmeta (del Departamento de Historia Medieval de la Universidad de Zaragoza) exponiendo la «Organización artesanocomercial de la ciudad musulmana». Seguidamente el Dr. Míkel de Epalza (de la Sección de Estudios Árabes e Islámicos de la Universidad de Alicante) leyó su aportación sobre los «Espacios y su funciones en la ciudad árabe» en la que expuso un modelo de trabajo lógico y estructurado para el urbanismo musulmán. Tras la ponencia del Dr. Epalza, se abrió un interesante debate y, seguidamente, después de un breve descanso, se pasó al turno de las comunicaciones; en el mismo, el Dr. Pedro Lavado Paradinas, leyó su aportación sobre "La ciudad mudéjar: espacios y nuevas funciones".

Dentro ya del turno de tarde, a las 17.00 horas la Dra. Manuel Marín leyó su ponencia sobre la «Ciencia, enseñanza y cultura en la ciudad árabe». A continuación, la Dra. María Jesús Rubiera Mata, (Directora del Departamento de Estudios Árabes e Islámicos de la Universidad de Alicantel expuso su interesante ponencia sobre los "Arquetipos ideales de la ciudad árabe" en base a los modelos literarios ideales sobre la misma. Después de unas palabras del Profesor Miège sobre la evolución de las perspectivas del estudio del agua en las ciudades islámicas desde hace un siglo en Europa, la Dra. Iskra Dandolova (de la Facultad de Arquitectura de la Universidad de Sofia) disertó sobre "La imaginación del agua en la ciudad ideal del futuro. Reflexiones».

El siguiente día, el domingo cuatro, se clausuró el Simposio sobre «La ciudad Islámica) con una excursión a Calatayud y Daroca (provincia de Zaragoza), que fueron importantes poblaciones estratégicas en el período musulmán. Organizada por la Institución Fernando el Católico acudimos en autocar primeramente a la ciudad de Calatayud. Allí, guiados por el Dr. José Luis Corral y el arqueólogo municipal señor García Marco, visitamos todo el casco antiguo de la ciudad y subimos para admirar las importantes defensas y sus fortalezas islámicas. Tras una extensa e interesantísima visita a esta población de origen islámico, que fue una de las llaves defensivas de la Marca Media de Al-Andalus, tomamos nuevamente el autocar para ir a comer a un gran restaurante de Daroca; después de ello, retomadas nuevas fuerzas, acudimos a ver la ciudad islámica de Daroca, la otra clave en la defensa de la Marca Media. En esta población visitamos primeramente el nuevo Museo Arqueológico, ubicado sobre una de las puertas de la muralla medieval. Seguidamente, guiados por el Dr. José Luis Corral se giró detenida visita a la ciudad, parándonos especialmente con el fin de observar los elementos que de su plano islámico que aún se conservan. Tras el efímero retorno al pasado islámico que supuso esta doble visita, retornamos a Zaragoza. 
Esperemos que una pronta publicación de las actas de esta reunión científica sea el colofón para este completo e interesante Simposio de Zaragoza sobre "La ciudad Islámica", para que pronto puedan estar al alcance de todos, tanto las aportaciones de gran nivel científico que tuvimos ocasión de oir los que en el Simposio estuvimos presentes, como los numerosos estudios presentados, que no pudieron llegar a leerse por su elevado número y falta de tiempo. 